\title{
Epidemiology and Estimated Cost of Surgery for Chronic Subdural Hematoma Conducted by the Unified Health System in Brazil (2008-2016)
}

\section{Epidemiologia e estimativa de custo das cirurgias para hematoma subdural crônico realizadas pelo Sistema Único de Saúde no Brasil (2008-2016)}

Marcelo José da Silva de Magalhães 1,2,3,4 Jéssica Pimenta Araújo ${ }^{2}$

Ana Luísa Aguiar Simões Alves Paulino ${ }^{2}$ Bárbara Helen Mendes Batista ${ }^{2}$ Danielle Gonçalves de Freitas ${ }^{2}$ Jéssica Daiane da Cruz Santos ${ }^{2}$ Natália Lopes de Paula Andrade ${ }^{2}$

${ }^{1}$ Department of Medicine, Faculdades Integradas Pitágoras de Montes Claros, Montes Claros, MG, Brazil

2 Department of Medicine, Faculdades Unidas do Norte de Minas, Montes Claros, MG, Brazil

3 Department of Neurosurgery, Hospital Aroldo Tourinho, Montes Claros, MG, Brazil

4 Department of Neurosurgery, Hospital Vila da Serra-Nova, Lima, MG, Brazil

Arq Bras Neurocir 2019;38:79-85.

\begin{abstract}
Address for correspondence Marcelo José da Silva de Magalhães, MD, MSc, Rua Francisco Versiane Athaide, 760, Cândida Câmara, 39401039 , Montes Claros, MG, Brazil (e-mail: marcelo7779@yahoo.com.br).
\end{abstract}

\begin{abstract}
Keywords

- epidemiology

- chronic subdural hematoma

- cost analysis

Introduction Chronic subdural hematoma (CSH) is one of the most frequent forms of intracranial hemorrhage. It is a collection of encapsulated, well-delimited fluid and/or coagulated blood in several clotting stages located between the dura mater and the arachnoid mater.

Objective To describe the epidemiological aspects of CSH described in the database of the Brazilian Unified Health System (SUS, in the Portuguese acronym) regarding admission numbers, hospitalization expenses, health care professional expenses, mortality rate, and death numbers by region from 2008 to the first half of 2016 .

Methods The present work was performed between August and September 2016 with a review about the epidemiological aspects of CSH in Brazil according to the Informatics Department of the Unified Health System (DATASUS) database, encompassing the period from January 2008 to June 2016, and to scientific papers from the past 10 years which were electronically published at the PubMed, Scielo, and LILACS databases.

Results From 2008 to the first half of 2016, the total values were the following: hospital admission authorizations (HAAs). 33,878; hospital expenses, BRL 65,909,429.22; health care professional expenses, BRL 25,158,683.21; deaths, 2,758; and mortality rates ranging from 6.47 to $12.63 \%$.
\end{abstract}

received

November 26, 2016

accepted

May 9, 2017
DOI https://doi.org/

10.1055/s-0037-1603761. ISSN 0103-5355.
Copyright ( 2019 by Thieme Revinter

Publicações Ltda, Rio de Janeiro, Brazil
License terms

(c) $(1) \$$ 


\section{Resumo}

\section{Palavras-chave \\ - epidemiologia \\ - hematoma subdural crônico \\ - análise de gastos}

Conclusion In spite of the high clinical relevance of $\mathrm{CSH}$, epidemiological studies about this condition are limited. As such, the present paper is an updated approach on $\mathrm{CSH}$, focusing on its epidemiological aspects according to the DATASUS database.

Introdução Hematoma subdural crônico (HSDC) é uma das formas mais frequentes de hemorragia intracraniana. É constituído por uma coleção de sangue fluido e/ou coagulado em vários estágios, encapsulada e bem delimitada, localizada entre a duramáter e a aracnoide-máter.

Objetivo Descrever aspectos epidemiológicos do HSDC, coletados no banco de dados do Sistema Único de Saúde (SUS), referentes aos gastos intrahospitalares, remuneração do profissional médico, taxa de mortalidade, e número de óbitos por região, de 2008 ao $1^{\circ}$ semestre de 2016 .

Métodos O presente trabalho foi realizado entre agosto e setembro de 2016, a partir de uma revisão da literatura sobre os aspectos epidemiológicos do HSDC no Brasil, com base no banco de dados do Departamento de Informática do Sistema Único de Saúde (DATASUS), compreendendo o período de janeiro de 2008 a junho de 2016, bem como em artigos científicos dos últimos 10 anos, publicados nos bancos de dados eletrônicos PubMed, Scielo e LILACS.

Resultados Dos aspectos analisados no período de 2008 ao $1^{\circ}$ semestre de 2016, foram encontrados os seguintes valores totais: autorizações de internação hospitalar (AlHs), 33.878; valor de serviço hospitalar, R\$ 65.909.429,22; valor dos serviços profissionais, $R \$ 25.158 .683,21$; dias de permanência, 304.746; óbitos, 2.758; e taxa de mortalidade, entre 6,47 e $12,63 \%$.

Conclusão Embora o HSDC represente um assunto de grande relevância clínica, entendese que ainda são escassos os estudos epidemiológicos que tratem do tema. Desta forma, o presente artigo traz uma abordagem atualizada para o tema, com enfoque em aspectos epidemiológicos nacionais do HSDC coletados no banco de dados do DATASUS.

\section{Introduction}

Chronic subdural hematoma (CSH) is one of the most common forms of intracranial hemorrhage. It is a collection of encapsulated, well-delimited fluid and/or coagulated blood in several clotting stages located between the dura-mater and the arachnoid mater. ${ }^{1,2}$

Chronic subdural hematoma is clinically important because, in most cases, its evolution without immediate surgical treatment can lead to high morbidity and mortality. Therefore, early diagnosis and successful surgical drainage are imperative to ensure a complete recovery. ${ }^{2,3}$

Although CSH is a highly frequent and clinically relevant disease, epidemiological data are still limited in Brazil. The present work aims to describe the epidemiological aspects of CSH according to the database of the Brazilian Unified Health System (SUS, in the Portuguese acronym). The following variables were studied from 2008 to the first half of 2016: admission numbers, hospitalization expenses, health care professional expenses, mortality rate, and death numbers.

\section{Materials and Methods}

Information on the surgical treatment of CSH was obtained from code 04.03.01.03.14 between January 2008 and June 2016; this code is used for issuing hospital admission authorizations (HAAs) at the Informatics Department of the Unified Health System (DATASUS, in the Portuguese acronym) virtual database. The present review evaluates admission numbers, hospitalization expenses, health care professional expenses, mortality rates, and death numbers during the period studied.

Scientific papers from the past 10 years which were electronically published at the PubMed, Scielo and LILACS databases were used in the present review. These papers were retrieved using the following descriptors in Portuguese and in English: epidemiologia/epidemiology and hematoma subdural crônico/chronic subdural hematoma. Initially, 119 papers were found at PubMed, 3 at Scielo, and 71 at LILACS. However, only 13 papers were used in the present review, since those that did not present epidemiological information on $\mathrm{CSH}$, such as prevalence and incidence, were excluded.

\section{Results}

According to - Table 1 and $\boldsymbol{- F i g . ~ 1 , ~ t h e r e ~ w e r e ~ 2 , 3 8 9 ~ H A A s ~ i n ~}$ 2008 , of which more than half were in the Southeast region $(1,284)$. Meanwhile, the Northern region had the lowest HAA index, with 101 cases. The number of HAAs increased over time, with a total number of 4,885 in 2015 , and of 2,453 HAAs in the first half of 2016. 
Table 1 Number of hospital admission authorizations (HAAs) approved per year for the chronic subdural hematoma surgical treatment code

\begin{tabular}{|l|l|l|l|l|l|l|l|}
\hline & North & Northeast & Southeast & South & Central-West & Total & Population estimate \\
\hline 2008 & 101 & 289 & 1,284 & 415 & 300 & 2,389 & $189,600,000$ \\
\hline 2009 & 169 & 479 & 1,676 & 515 & 403 & 3,242 & $191,480,630$ \\
\hline 2010 & 223 & 533 & 1,906 & 599 & 471 & 3,732 & $190,755,799$ \\
\hline 2011 & 193 & 601 & 2,060 & 640 & 512 & 4,006 & - \\
\hline 2012 & 207 & 645 & 2,127 & 643 & 483 & 4,105 & $193,946,886$ \\
\hline 2013 & 230 & 747 & 2,209 & 722 & 484 & 4,392 & $201,032,714$ \\
\hline 2014 & 230 & 759 & 2,380 & 768 & 537 & 4,674 & $202,768,562$ \\
\hline 2015 & 213 & 808 & 2,540 & 706 & 618 & 4,885 & $204,450,649$ \\
\hline $2016 *$ & 95 & 410 & 1,260 & 392 & 296 & 2,453 & $206,391,315$ \\
\hline Total & 1,661 & 5,271 & 17,442 & 5,400 & 4,104 & 33,878 & - \\
\hline Average & 184.55 & 585.66 & 1,938 & 600 & 456 & - & - \\
\hline
\end{tabular}

*Data from 2016 correspond to the first semester. Source: DATASUS/IBGE (http://tabnet.datasus.gov.br/cgi/tabcgi.exe?sih/cnv/qiuf.def). Accessed on September 1, 2016.

- Table 2 shows that hospital expenses also increased over the years. In 2008, the total expense was of BRL $3,803,093.70$ and, in 2015, of BRL 10,319,288.77; the highest value was reached in the Southeast region, followed by the South and Central-West regions. In the following years, the Northeast region assumed the $3^{\text {rd }}$ position regarding hospital-specific expenses, with BRL 855,176.35 in 2011, and BRL 1,681,269.55 in 2015.

Regarding health care professional expenses, the Southeast region surpassed the other regions, with an amount of BRL 2,121,365.37 in 2015, and of BRL 700,318.46 in 2008. The North region, however, presented lower values compared with the remaining regions, with BRL 188,139.34 in 2015, and BRL 53,762.80 in 2008. Although the expenses with the surgical treatment of CSH were higher in the Southeast region, the highest growth in expenses during the evaluated period occurred at the Northeast region, whose 2015 figures were 4 times higher than those observed in 2008 ( - Table 3 ).
Regarding the number of deaths per region, in 2008, the Southeast region presented the highest number, with 104 cases, followed by the South region, with 43 , the Northeast region, with 31, the Central-West region, with 20 , and the North region, with 2 cases. This proportion was sustained until 2011, when the Northeast region surpassed the South region, with 53 deaths, while the Southeast region continued to present the largest number of deaths, 181. From 2014 to 2015 , there was a significant increase in deaths in the Southeast region, with 216 and 218 cases, respectively. It is important to note that the number of deaths mentioned above did not reflect the mortality rate from each region ( - Table 4 ).

Regarding the mortality rate (ratio between the number of deaths and the number of approved HAAs, computed as admissions during the period, multiplied by 100), the Northeast region surpassed the other regions in 2008, with 10.73. In 2009, the Southeast came in first place, with 9.19; and the Northeast had the lowest mortality rate, of 6.47. The mortality

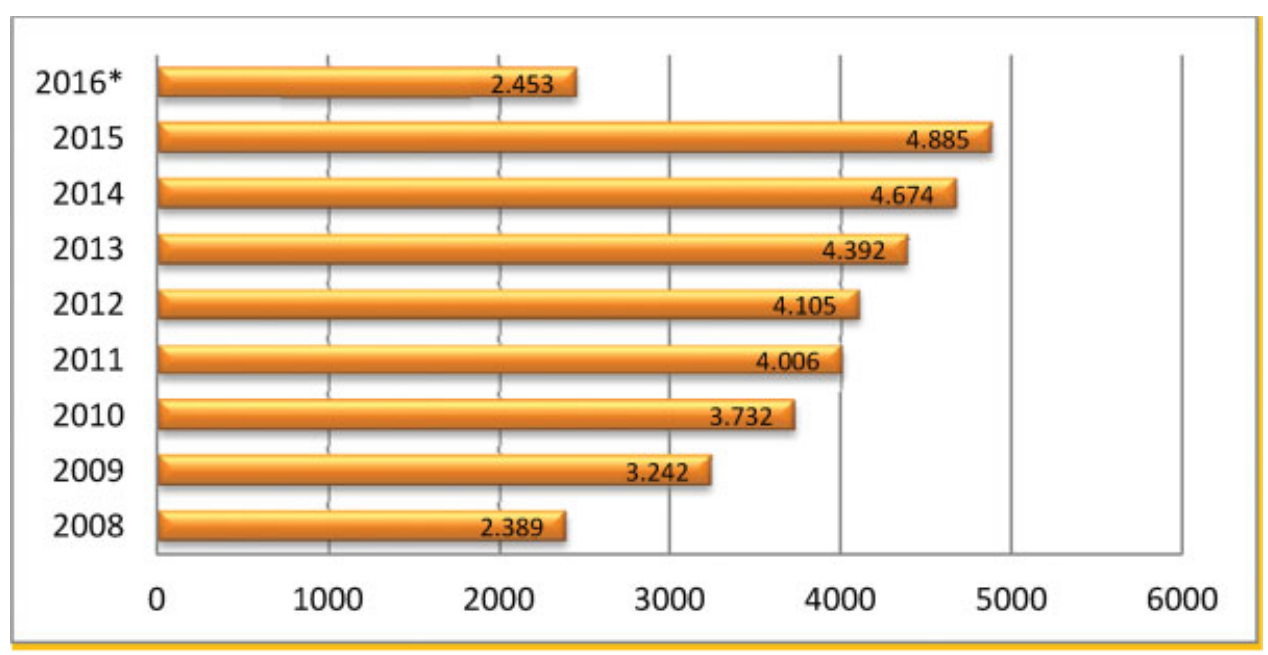

Fig. 1 Number of hospital admission authorizations (HAAs) approved per year for the chronic subdural hematoma surgical treatment code. *Data from 2016 correspond to the first semester. Source: DATASUS. Accessed on September 1, 2016. 
82 Epidemiology and Estimated Cost of Surgery for Chronic Magalhães et al.

Table 2 Hospital expenses (in BRL) per year for the chronic subdural hematoma surgical treatment code

\begin{tabular}{|l|l|l|l|l|l|l|}
\hline & North & Northeast & Southeast & South & Central-West & Total \\
\hline 2008 & $142,396.23$ & $366,680.83$ & $1,993,721.28$ & $878,814.47$ & $421,480.89$ & $3,803,093.70$ \\
\hline 2009 & $288,533.57$ & $605,903.04$ & $2,759,078.36$ & $1,177,276.80$ & $742,875.76$ & $5,573,667.53$ \\
\hline 2010 & $399,103.93$ & $689,638.94$ & $3,434,604.02$ & $1,405,519.81$ & $870,073.75$ & $6,798,940.45$ \\
\hline 2011 & $356,896.29$ & $855,176.35$ & $3,840,565.12$ & $1,566,255.29$ & $834,296.26$ & $7,453,189.31$ \\
\hline 2012 & $421,962.60$ & $1,064,555.36$ & $4,293,906.36$ & $1,580,971.21$ & $811,095.93$ & $8,172,491.46$ \\
\hline 2013 & $456,460.13$ & $1,314,112.97$ & $4,435,818.31$ & $1,710,917.57$ & $844,060.34$ & $8,761,369.32$ \\
\hline 2014 & $420,430.72$ & $1,419,506.18$ & $4,902,076.14$ & $1,970,913.28$ & $1,102,661.80$ & $9,815,588.12$ \\
\hline 2015 & $466,275.23$ & $1,681,269.55$ & $5,271,961.14$ & $1,760,071.79$ & $1,139,711.06$ & $10,319,288.77$ \\
\hline $2016^{*}$ & $185,630.52$ & $735,221.44$ & $2,686,763.48$ & $1,043,346.61$ & $560,838.51$ & $5,211,800.56$ \\
\hline Total & $3,137,689.22$ & $8,732,064.66$ & $33,618,494.21$ & $13,094,086.83$ & $7,327,094.30$ & $65,909,429.22$ \\
\hline Average & $348,632.14$ & $970,229.41$ & $3,735,388.25$ & $1,454,898.54$ & $814,121.59$ & - \\
\hline
\end{tabular}

*Data from 2016 correspond to the first semester. Source: DATASUS (http://tabnet.datasus.gov.br/cgi/tabcgi.exe?sih/cnv/qiuf.def). Accessed on September 1, 2016.

Table 3 Health care professional expenses (in BRL) for the chronic subdural hematoma surgical treatment code

\begin{tabular}{|l|l|l|l|l|l|l|}
\hline Region & North & Northeast & Southeast & South & Central-West & Total \\
\hline 2008 & $53,762.80$ & $141,443.90$ & $700,318.46$ & $247,544.28$ & $155,470.16$ & $1,298,539.60$ \\
\hline 2009 & $97,828.75$ & $236,906.46$ & $932,017.33$ & $316,638.23$ & $237,877.98$ & $1,821,268.75$ \\
\hline 2010 & $131,841.80$ & $269,179.70$ & $1,134,175.59$ & $377,252.52$ & $289,015.45$ & $2,201,465.06$ \\
\hline 2011 & $140,023.38$ & $380,987.59$ & $1,471,347.18$ & $482,553.69$ & $358,388.00$ & $2,833,299.84$ \\
\hline 2012 & $180,931.30$ & $492,039.69$ & $1,778,718.92$ & $548,813.49$ & $385,851.03$ & $3,386,354.43$ \\
\hline 2013 & $196,851.19$ & $569,261.68$ & $1,825,123.26$ & $601,079.45$ & $389,804.15$ & $3,582,119.73$ \\
\hline 2014 & $185,939.20$ & $589,062.45$ & $1,981,432.59$ & $657,176.98$ & $452,894.78$ & $3,866,506.00$ \\
\hline 2015 & $188,139.34$ & $648,661.78$ & $2,121,365.37$ & $600,818.21$ & $511,468.30$ & $4,070,453.00$ \\
\hline $2016 *$ & $89,461.94$ & $312,593.27$ & $1,059,720.20$ & $350,981.53$ & $285,919.86$ & $2,098,676.80$ \\
\hline Total & $1,264,779.70$ & $3,640,136.52$ & $13,004,218.90$ & $4,182,858.38$ & $3,066,689.71$ & $25,158,683.21$ \\
\hline Average & $140,531.08$ & $404,459.61$ & $1,444,913.21$ & $464,762.04$ & $340,743.30$ & - \\
\hline
\end{tabular}

*Data from 2016 correspond to the first semester. Source: DATASUS (http://tabnet.datasus.gov.br/cgi/tabcgi.exe?sih/cnv/qiuf.def). Accessed on Sep 1, 2016.

Table 4 Number of deaths related to the chronic subdural hematoma surgical treatment code

\begin{tabular}{|c|c|c|c|c|c|c|}
\hline & North & Northeast & Southeast & South & Central West & Total \\
\hline 2008 & 9 & 31 & 104 & 43 & 20 & 207 \\
\hline 2009 & 14 & 31 & 154 & 44 & 29 & 272 \\
\hline 2010 & 31 & 51 & 151 & 42 & 30 & 305 \\
\hline 2011 & 18 & 53 & 181 & 45 & 39 & 336 \\
\hline 2012 & 21 & 42 & 173 & 46 & 16 & 298 \\
\hline 2013 & 26 & 70 & 174 & 58 & 26 & 354 \\
\hline 2014 & 23 & 65 & 216 & 39 & 28 & 371 \\
\hline 2015 & 21 & 84 & 218 & 60 & 30 & 413 \\
\hline $2016^{*}$ & 12 & 36 & 111 & 27 & 16 & 202 \\
\hline Total & 175 & 463 & 1,482 & 404 & 234 & 2,758 \\
\hline Average & 19.44 & 51.44 & 164.66 & 44.88 & 26 & - \\
\hline
\end{tabular}

*Data from 2016 correspond to the first semester. Source: DATASUS (http://tabnet.datasus.gov.br/cgi/tabcgi.exe?sih/cnv/qiuf.def). Accessed on September 1, 2016. 
Table 5 Mortality rate related to the chronic subdural hematoma surgical treatment code

\begin{tabular}{|l|l|l|l|l|l|l|}
\hline & North & Northeast & Southeast & South & Central-West & Total \\
\hline 2008 & 8.91 & 10.73 & 8.10 & 10.36 & 6.67 & 44.77 \\
\hline 2009 & 8.28 & 6.47 & 9.19 & 8.54 & 7.20 & 39.68 \\
\hline 2010 & 13.70 & 9.57 & 7.92 & 7.01 & 6.37 & 44.57 \\
\hline 2011 & 9.33 & 8.82 & 8.79 & 7.03 & 7.62 & 41.59 \\
\hline 2012 & 10.14 & 6.51 & 8.13 & 7.15 & 3.31 & 35.24 \\
\hline 2013 & 11.30 & 9.37 & 7.88 & 8.03 & 5.37 & 41.95 \\
\hline 2014 & 10.00 & 8.56 & 9.08 & 5.08 & 5.21 & 37.93 \\
\hline 2015 & 9.86 & 10.40 & 8.58 & 8.50 & 4.85 & 42.19 \\
\hline $2016^{*}$ & 12.63 & 8.78 & 8.81 & 6.89 & 5.41 & 42.52 \\
\hline Total & 94.15 & 79.21 & 76.48 & 68.59 & 52.01 & 370.44 \\
\hline Average & 10.46 & 8.8 & 8.49 & 7.62 & 5.77 & - \\
\hline
\end{tabular}

*Data from 2016 correspond to the first semester. Source: DATASUS (http://tabnet.datasus.gov.br/cgi/tabcgi.exe?sih/cnv/qiuf.def). Accessed on September 1, 2016.

rate has changed in all regions during these years, so that in 2012,2013 , and 2014, the highest rates were observed in the North region, with $10.14,11.30$, and 10.0, respectively. In 2015 , the Northeast region returned to the first place, with 10.40; in 2016, from January to June, the North region had the highest mortality rate, with 12.63 ( - Table 5 ).

\section{Discussion}

In 1657, Johannes Breakfast Wepfer found a large cyst filled with blood under the dura mater of a patient who had suffered a stroke. In 1817, Houssard discovered that the cyst previously described was a membrane-covered clot; the histology and formation of this lesion were described by Virchow, in 1857, who also called it internal hemorrhagic pachymeningitis. Next, Trotter defended the theory of trauma in drainage veins for the superior longitudinal sinus of the subdural hemorrhagic cyst, consolidating its traumatic etiology in 1914. In 1925, internal hemorrhagic pachymeningitis was renamed $\mathrm{CSH}^{1,4,5}$

Subdural hematomas can be classified as acute, subacute and chronic, according to the time elapsed after the triggering factor. An acute subdural hematoma occurs within 72 hours after the trauma; a subacute hematoma, between 72 hours and 20 days posttrauma; and a chronic hematoma, 20 days posttrauma. Acute hematomas affect mainly young adults, whereas chronic hematomas affect the elderly population. ${ }^{1,6}$

The risk factors and associated diseases for CSHs include trauma, systemic arterial hypertension, neurological diseases (cerebrovascular conditions, malformations and neoplasms), male gender, higher age ( $>50$ years old), Caucasian ethnicity, alcoholism, diabetes mellitus, cardiovascular diseases, smoking, cerebrovascular diseases, kidney diseases, epilepsy, blood dyscrasias, lung diseases, psychiatric history, and positive human immunodeficiency virus (HIV) serology. ${ }^{1,7}$

Epidemiologically, CSH is most commonly found in the $7^{\text {th }}$ decade of life. A male predominance is observed in $\sim 70$ to
$90 \%$ of the cases. Its incidence has increased worldwide due to the increase in the populational life expectancy; moreover, it is believed that, in a few years, CSH treatment will be the most performed neurosurgical procedure, surpassing the resection of primary and metastatic tumors. $2,8,9$

The pathophysiology of CSH is not fully understood. The main theories regarding its emergence include the osmotic theory and the recurrent bleeding theory in encapsulated hematomas. The first one is based on the idea that the liquefaction of the hematoma increases the osmotic pressure and the protein content, with the consequent attraction of adjacent fluids to the cavity through a semipermeable membrane. The second theory, of the recurrent bleeding, is more accepted and states that the blood vessels and the abnormal capsule of the hematoma are more subject to bleeding. It is noteworthy that the outer CSH membrane is rich in vessels, with large capillaries, but lacking smooth muscles in its wall..$^{7-9}$ Classically, CSH results from a traumatic lesion of the parasagittal Mittenzweig vessels. The causes of nontraumatic CSHs include arteriovenous malformations, intracranial aneurysms, coagulopathies, cerebral convexity tumors, and meningeal carcinomatosis. ${ }^{1,3}$

Among the signs and symptoms found in patients with these characteristics, headache is present in $\sim 80 \%$ of the cases, as well as a mentation change that can manifest itself in different degrees: confusion, somnolence, or coma. These patients may still present focal neurological deficits, such as hemiparesis (observed in up to $56 \%$ of the cases). Some atypical presentations were cited in selected studies, such as isolated neurological deficits (vertigo, nystagmus, and oculomotor paralysis), and extrapyramidal syndromes with a predominance of parkinsonian symptoms. 2,7,10

Differential diagnoses include stroke, subarachnoid hemorrhage, and tumors. ${ }^{2}$ At a computed tomography (CT) of the skull, CSH presents as a hypodensity. Although less used, a magnetic resonance imaging (MRI) of the skull can also be requested in cases in which the CT has some degree of limitation, as in cases of small-volume CSHs. ${ }^{1,7,10}$ 
The treatment for CSH may be conservative or surgical. Nonsurgical treatments include absolute rest, and use of steroids, mannitol, and other hypertonic solutions. ${ }^{1,7}$ It is worth mentioning that the conservative clinical treatment is not indicated for most cases, since surgery is aimed at preventing clinical worsening, neurological deficits, or even death. Currently, the best option is the surgical treatment, which can often be performed through trepanation or craniotomy, with or without postoperative drainage placement. ${ }^{1,7}$

After the surgery, recurrences are not uncommon; they are related to three factors: the patient (age, gender, ethnicity, bleeding tendency, and involved comorbidities), the pathophysiology of the hematoma, and the surgical process. Possible postoperative complications include acute subdural hematoma, intracranial hypertensive hemorrhage, and hypertensive pneumocephalus. However, postoperative healing and recovery rates are high., ${ }^{1,6}$

Pereira et $\mathrm{al}^{11}$ report that the annual incidence of CSH in the general population ranges from 1.72 to 7.35 per 100,000 people, according to aging, with a higher value found in the $8^{\text {th }}$ decade of life. It is estimated that this incidence will continue to grow steadily as the life expectancy increases.

In Japan, where the elderly population grows faster compared with other countries, the annual incidence of CSH is 20.6 per 100,000 people, with 76.5 per 100,000 people in the $8^{\text {th }}$ decade of life, and with 127.1 per 100,000 people in individuals $>80$ years old. ${ }^{12}$ A study conducted in the United States found an annual incidence rate of 79.6 per 100,000 people in the elderly population. The same study also predicted an increase in the number of cases by 2030 , reaching 121.4 per 100,000 people in this specific population, and 17.6 per 100,000 people in other age groups, totaling $\sim 60,000$ cases per year in the USA. ${ }^{13}$

There is limited data on the general incidence of CSH in Brazil. However, it can be inferred from the present paper that, in 2015, the number of hospitalizations due to CSH corresponded to $0.0023 \%$ of the population, or 2.39 hospital admissions per 100,000 inhabitants. It should be remembered, however, that the number of hospitalizations does not represent a reliable incidence in the country. This bias could be explained by the noninclusion of selected patients treated in the private health care system.

According to the DATASUS, from 2008 to the $1^{\text {st }}$ semester of 2016, there were 33,878 hospital admissions; the Southeast region had the highest number of hospital admissions, with 17,442 hospitalizations, and an annual average number of 2,325.6. The North region had the lowest number of hospital admissions, 1,661, with an annual average of 221.5. Consequently, the Southeast and North regions, respectively, have the highest and lowest indices of hospital expenses, of health care professional expenses, and of number of deaths. The mortality rate was not affected by this rule, since the numbers were higher in the North region.

During the same period, 33,878 CSH-related hospitalizations generated a total hospital expense of BRL 65,909,429.22, and health care professional expenses of BRL 25,158,683.21. In the South region, the average hospitalization and health care professional expenses were of BRL 2,424.83 and BRL 774.61, respectively.

The total number of deaths by CSH during the evaluated period was 2,758 , with the largest number, 1,482 , in the Southeast region, followed by 463 in the Northeast region, 404 in the South region, 234 in the Central-West region, and 175 in the North region. It is worth mentioning that the mortality rate ranged from 6.47 to 12.63 per 100,000 patients during the period studied.

Thus, the obtained data allows inferring that a patient admitted due to CSH generated hospital expenses of BRL $1,945.50$, and professional expenses of BRL 742.62. A hospitalization day cost BRL 216.16.

During the preparation of the present paper, the noncomprehensiveness of data from surgeries performed by the private health system and health insurance companies was considered a limitation, since our purpose was to collect information from procedures performed by the SUS. In addition, there is a marked scarcity of Brazilian and worldwide epidemiological contents related to the incidence and prevalence of $\mathrm{CSH}$. Another possible bias of the present study was the probability of multiple and/or erroneous diagnoses inclusion in the results found in the DATASUS database.

\section{Conclusion}

The incidence of CSH has increased in Brazil and worldwide. It is a benign pathology when diagnosed early, since its main approach is surgical treatment. According to the DATASUS database, from 2008 to the $1^{\text {st }}$ semester of 2016, there were a total of 33,878 hospital admissions for surgical CSH treatment. The total number of deaths from this disease during the same period was 2,758 , and the mortality rate ranged from 6.47 to $12.63 \%$. These admissions totaled hospital expenses of BRL 65,909,429.22, and health care professional services expenses of BRL 25,158,683.21. Although CSH is a clinically relevant disease, there are few epidemiological studies about it. Thus, the present paper approaches the Brazilian epidemiological aspects of $\mathrm{CSH}$.

Conflicts of Interest

The authors have no conflicts of interest to declare.

\section{References}

1 Adhiyaman V, Asghar M, Ganeshram KN, Bhowmick BK. Chronic subdural haematoma in the elderly. Postgrad Med J 2002;78 (916):71-75

2 Yasuda CL, Morita ME, Nishimori FY, Yasuda AM, Alves HL. Hematoma subdural crônico: estudo de 161 pacientes operados e a relação com alterações no coagulograma. Arq Neuropsiquiatr 2003;61(04):1011-1014

3 Javadi SA, Naderi F, Javadi AM. The Optimal surgical approach for treatment of chronic subdural hematoma: questionnaire assessment of practice in Iran and review of literature. Acta Med Iran 2015;53(10):617-621

4 Lee KS. History of chronic subdural hematoma. Korean J Neurotrauma 2015;11(02):27-34 
5 Lee KS. Chronic subdural hematoma in the aged, trauma or degeneration? J Korean Neurosurg Soc 2016;59(01):1-5

6 Ivamoto HS, Lemos HP Jr, Atallah AN. Surgical treatments for chronic subdural hematomas: a comprehensive systematic review. World Neurosurg 2016;86:399-418

7 Iliescu IA. Current diagnosis and treatment of chronic subdural haematomas. J Med Life 2015;8(03):278-284

8 Farhat Neto J, Araújo JL, Ferraz VR, Haddad L, Veiga JC. Chronic subdural hematoma: epidemiological and prognostic analysis of 176 cases. Rev Col Bras Cir 2015;42(05):283-287

9 Gelabert-González M, Arán-Echabe E, Bandín-Diéguez FJ, et al. [Bilateral chronic subdural haematoma: Analysis of a series of 190 patients]. Neurocirugia (Astur) 2016;27(03):103-111
10 Iliescu IA, Constantinescu AI. Clinical evolutional aspects of chronic subdural haematomas - literature review. J Med Life 2015;8(Spec Issue):26-33

11 Pereira CU, Dantas MC, Santos EAS, Santos CMT, Monteiro JTS. Hematoma subdural crônico no idoso. Rev Bras Med 2006;63(07): 331-337

12 Karibe H, Kameyama M, Kawase M, Hirano T, Kawaguchi T, Tominaga T. [Epidemiology of chronic subdural hematomas]. No Shinkei Geka 2011;39(12):1149-1153

13 Balser D, Farooq S, Mehmood T, Reyes M, Samadani U. Actual and projected incidence rates for chronic subdural hematomas in United States Veterans Administration and civilian populations. J Neurosurg 2015;123(05):1209-1215 